\title{
Magnetic Resonance Imaging Evaluation Of The Degeneration Of The Multifidus And Erector Spinae Muscles In Patients With Chronic Mechanical Low Back Pain, Patients With Herniated Disc, And Healthy Individuals
}

Alikemal Yazici ( $\sim$ alikemalyazici@hotmail.com)

Near East University

Tuba Yerlikaya

Near East University

Adile Oniz

Near East University

\section{Research Article}

Keywords: Low back pain, multifidus, erector spinae, cross-sectional area, fat infiltration, magnetic resonance imaging

Posted Date: February 11th, 2022

DOI: https://doi.org/10.21203/rs.3.rs-1332224/v1

License: @ (i) This work is licensed under a Creative Commons Attribution 4.0 International License. Read Full License 


\section{Abstract}

Background: The determination of appropriate treatment methods for patients with chronic low back pain may be possible with the determination of the cause of the pain. Therefore, it can be considered that identification of the morphological changes of the paraspinal muscles in patients with chronic low back pain and comparison with control subjects is necessary to explain the relationship of these with pain. The aim of this study was to examine degeneration in the lumbar musculus multifidus (LMF) and lumbar musculus erector spinae (LES) in patients with mechanical chronic low back pain, patients with chronic low back pain with lumbar herniated disc and no radiculopathy, and healthy individuals, and through comparison of the results according to gender, pain and lumbar segments, to examine the relationship with low back pain.

Material and Method: The study included 35 patients with mechanical low back pain, 38 patients with lumbar herniated disc and no radiculopathy, and a control group of 36 healthy subjects. The patients were evaluated in respect of LMF and LES cross-sectional area (CSA), total CSA (TCSA=LMF+LES), fat infiltration and asymmetry on axial magnetic resonance imaging (MRI) slices at the L3-S1 level.

Results: The mean CSA values of the right and left LMF and LES showed significant differences between the groups $(p<0.001, p=0.002, p=0.002, p=0.010$, respectively). The mean values obtained in the healthy control group were lower than those of the other two groups. Fat infiltrations showed a difference between the right-left LMF and left LES groups ( $p=0.007$, $p<0.001, p=0.026$, respectively). Asymmetry was not observed between the CSA and TCSA of the right and left sides. No significant relationship was determined between the duration of low back pain and the CSA and TCSA values and fat infiltration.

Conclusion: A relationship was determined between fat infiltration in LMF and mechanical low back pain and LDH. The low CSA and TCSA values in the healthy control group suggest that it is due to a pseudohyertrophy mechanism. This shows that when evaluating muscle mass, rather than CSA and TCSA, the functional cross-sectional area (FCSA) or muscle atrophy associated with fat infiltration should be measured.

\section{Background}

Low back pain (LBP) is a problem widely seen in the general population, which is a social, psychological, and economic burden [1]. After upper respiratory tract infections, it is the second most common reason for seeing a doctor [2], and is the most common reason for restricting activity in individuals aged $<45$ years [3]. LBP is experienced at least once a year by $15 \%-20 \%$ of adults, and at least once during the lifetime in $50 \%-80 \%$ [1]. This renders it a socioeconomic health problem due to long-term morbidity, with loss of workforce causing high costs [4]. Although LBP is seen so often, the pathophysiology is still not fully understood and there is insufficient correlaton between research findings and symptoms [2]. The causes of LBP include lifestyle, working conditions, traumatic events, demographic characteristics, congenital malformations, and infectious, inflammatory, metabolic, neurogenic, neoplastic, and several other factors [1].

The paraspinal muscles play a role in the structural and functional stabilisation of the lumbar spine. The paraspinal muscles are formed of the superficial muscle layer responsible for spine and extremity movements, which primarily control intersegmentary movement, and the deep muscle layer (LMF and LES), which function in lumbar stabilisation [5]. The LMF starts from the spinous processes of the L1-L5 vertebrae and terminate at the level of the L2-L5 vertebrae. The LES is formed from the $\mathrm{m}$. longissimus and the $\mathrm{m}$. iliocostalis and extends lateral of the LMF [6-9]. The primary function of the paraspinal muscles is to provide extension of the spine. In addition, when the LES moves unilaterally, it assists lateral flexion. Biomechanical and morphological studies have shown that the LMF has a good capacity for segmental support and control, but remains insufficient in creating turning moment. In contrast, while the LES forms good turning moment, it is not as effective as the LMF for spinal orientation control. Compared to all the other lumbar muscles, the LMF is short, thick, and has a large cross-sectional area (CSA). These properties allow the LMF to produce very large forces in a short time and 
make the LMF ideal for stability [10-13]. In contrast to the multisegmental innervation of the paraspinal muscle system, the LMF has unilateral innervation originating from the medial branch of the posterior root of the segmental nerve [14].

Fat infiltration (fat tissue entering muscle tissue), fibrosis (collagen connective tissue replacing normal muscle tissue) and atrophy (reduced contractile protein volume, that is, reduced cross-sectional area of the muscle and muscle cells) have been stated as the characteristics of muscle degeneration [15-19]. In the process of muscle degeneration, a decrease in muscle dimensions, an increase in adipose tissue activation, and early fat infiltration are seen in the acute period, and in the subacute period, type I slow muscle fibres transform to type II rapid muscle fibres (type I fibres are responsible for muscle strength and endurance), changes occur at the cellular and molecular level, fibrosis develops, and there is an increase in fat infiltration. The chronic period refers to the continued increase in atrophy of the muscle and muscle fibres, fibrosis and fat infiltration $[12,13,20-24]$. In a study by Pakkola et al, there was shown to be $9 \%$ fat infiltration in the paraspinal muscles of healthy middle-aged volunteers [16].

Several studies have been conducted to determine the condition of the paraspinal muscles in patients with LBP, and these studies have produced different results. Periods of 3 months, 6 months, and 1 year have been accepted as chronic LBP, degeneration of the paraspinal muscles has been observed in less than 1 year and there has been reported to be no change after 1 year [5, 25-27]. The size of the paraspinal muscles has been associated with gender [28-31], Body Mass Index (BMI) $[25,30,32,33]$, level of physical activity, and familial history [32]. The combined effects of familial genes and the shared early environment have been reported to be the strongest indicator of paraspinal muscle parameters [25]. Some studies have stated that fat and fibrotic changes have been observed histologically in muscle biopsies taken intraoperatively from patients with lumbar disc herniation (LDH) [34, 35]. Experimental studies have reported that in chronic LBP patients there are more type I rapid glycolytic fibres than type I slow oxidative fibres in the LMF and LES [20,36,37], that this type of fibre structure emerges with symptom duration [20] and this type of fibre structure leads to fatigue and less resistant paraspinal muscles [38].

Magnetic resonance imaging (MRI) is a non-invasive method for the evaluation of the paraspinal muscle tissue structure and components, which has come into widespread use in recent years for the detection of changes associated with diseases, response to injuries, or mechanical stress [39,40]. MRI provides a clear image with high resolution and contrast for soft tissue, without radiation exposure, giving information about muscle CSA and fat infiltration. It has also been stated that the reliability of MRI is slightly better than that of computed tomography (CT) [41].

The aim of this study was to examine the morphology of the multifidus and erector spinae muscles in patients with chronic low back pain of mechanical and lumbar herniated disc origin, and a healthy control group and to determine whether or not different treatment approaches are required for these patient groups, especally for the treatment of LBP. A secondary aim was to evaluate the relationships in all three groups between the size and fat infiltration of the paraspinal muscles and the age, gender, BMI, and level of segmental involvement (L3-L4,L4-L5,L5-S1). A third aim was to evaluate the relationship between the size of the paraspinal muscles, fat infiltration, and the duration and severity of pain in the mechanical LBP and lumbar disc herniated groups.

\section{Material And Method}

\section{Participants}

This observational case-control study was conducted with 109 participants between November 2020 and February 2021. A healthy control group was formed from volunteers who responded to the invitation on social media and in announcements, and described no LBP in the last year and were determined with no lumbar back problems in physical or radiological examination. The mechanical low back pain (non-specific LBP) patient group was formed of 35 patients who presented at the Orthopaedics and Traumatology Department with complaints of lumbar back pain, had no additional lumbar problem, and no additional lumbar problem was determined in physical and radiological examinations, or in laboratory tests. The 
lumbar disc herniation (LDH) group included 38 patients determined with lumbar disc herniation only on MRI, with no findings of root compression on examination and no complaints of radicular pain. EMG was requested for patients when there was suspicion of root compression. Patients determined with root compression on MRI and EMG, and those with degenerative disc disorders were not included in the herniated lumbar disc group. The subjects in all 3 groups were aged 2065 years. The patients in the mechanical LBP group and in the LDH group were selected at random from patients with LBP ongoing for 3 months. Both groups were similar in respect of the pain duration (chronic pain) and character (widespread pain for which localisation in the low back could not be clearly stated).

LBP was defined as pain between the lower border of the costae and the gluteal fold. Patients with inflammatory (eg, ankylosing spondylitis), infectious, metabolic, neoplastic, neurogenic, or hip and pelvis disorders, with limb shortness, vertebral fracture, structural deformity malformations (scoliosis, kyphosis), or a history of lumbar surgery were excluded from the study. The demographic, clinical, and disease-related data of all the subjects were obtained in face-to-face interviews. Hemogram, erythrocyte sedimentation rate, full urine analysis, salmonella, brucella, anti-streptolysin O (ASO), rheumatoid factor (RF), and C-reactive protein (CRP) tests were applied to patients when a differential diagnosis was necessary. Pain severity was evaluated with Visual Analog Scale (VAS).

The examinations of 109 patients were made by the same experienced spine surgeon and the lumbar spine MR images were analyzed by the same experienced radiology specialist, who was blinded to the clinical history. All the MRIs were taken by the same radiology technician. In the physical examination for differential diagnosis, specific lumbar segmental instability orthopaedic tests were applied (paravertebral intervertebral movement test, prone instability test) and the specific tests applied to determine radiculopathy (straight leg raise test, contralaateral straight leg raise, laseque test, femoral nerve tension test) in herniated lumbar disc were negative. There was no loss of strength or sensory loss associated with nerve root compression in any of the patients. In the radiological examinations, no findings were determined on direct radiographs suggestive of fracture, deformity, infection, or neoplasm. The hernia types were classified according to the localisation of the protruding part of the disc, as median, paramedian, foraminal, or extraforaminal, and as bulging, protrusion, extrusion, or sequestration, based on the degree of protrusion $[42,43]$. As there was no radiculopathy in any of the patients, there was no need for an MRI-based nerve compression grading system.

Approval for the study was granted by the Local Ethics Committee (YDU/2020/83-1160). Signed informed consent was obtained from all the study participants before inclusion.

\section{Measurements}

\section{Magnetic Resonance Imaging}

Imaging was performed with a 1.5 Tesla MR device (Signa Explorer SV25.3 16 channel, up-to-date software, General Electric, Milwaukee, WI, USA). Following adjustment for the localisation, shots were taken with the patient positioned supine, with a routine protocol for the lumbar spine with the measurement level between L3-S1 at the center of the disc (Figure 1). Turbo spin-echo T1 and T2-weighted sagittal and turbo spin-echo T2 axial 4mm sections parallel to the disc spaces were taken. The fat content and CSA of the lumbar musculus multifidus and erector spinae were measured bilaterally at L3-S1 levels, with each level examined separately for comparisons of the CSA and TCSA and of left and right asymmetry. This range was included as diseases of the lumbar region are usually seen in the lower lumbar region (L3-S1) and the upper lumbar spine region was not included. In a study by Kalichmann et al of CSA and fat infiltration of the paraspinal muscles, inter-observer reliability was reported to be moderate and the intra-observer agreement was excellent for the measurements on MRI [44].

There is no consensus about the T1 and T2-weighted sequences used in MRI. In most studies, degeneration has been classified using axial images. It has been stated that muscle, fat, and fascial structures are more easily determined and differentiated on T2-weighted slices (Figure 1) [45]. Therefore, if the evaluation is semiquantitative, errors will be reduced to a minimum. 
In the current study, the fascial borders (epimysium) of the CSA muscles were determined and measured using PACS report (picture archiving and communication system) imaging and manual drawing. Fat infiltration of the muscles was evaluated semiquantitatively as 1 st degree: normal ( $<10 \%$ fat infiltration of the CSA), 2 nd degree: moderate ( $10 \%-50 \%$ fat infiltration), and 3rd degree: severe ( $>50 \%$ fat infiltration) (Figure 2$)[2,14,17,44]$. Asymmetry was defined according to the larger side at L3-L4, L4-L5, and L5-S1 results. Asymmetry was calculated as "the largest edge - the smallest edge/ the largest edge $\times 100 "$ and stated as a percentage (\%) [46].

For internal reliability, 13 randomly selected patients were re-evaluated by the same radiologist after an interval of one month. The intra-observer kappa agreement value obtained was 0.941 .

\section{Statistical Analysis}

Data obtained in the study were analyzed statistically using SPSS vn. 23 software (IBM, Chicago, IL, USA). Taking the CSA mean values into consideration, it was determined to be necessary to have a minimum sample size of 78 subjects for $95 \%$ confidence (1- $\alpha), 95 \%$ test power $(1-\beta)$ and effect size of $f=0.461$. To allow for patient losses, the study was completed with a total of 109 subjects. According to the post hoc power analysis, the test power with 109 subjects was determined as $99.3 \%[47]$.

Conformity of the data to normal distribution was assessed with the Kolmogorov-Smirnov test. In the comparisons of data not showing normal distribution, the Kruskal Wallis and Mann Whitney U-tests were applied. The main effects of group, gender, and segment on CSA and TCSA were examined with the MANCOVA test taking age and BMI as covariate variables. The Bonferroni test was used in multiple comparisons. In the examinations of categorical data according to groups, the Chisquare test was used. A value of $p<0.05$ was accepted as statistically significant. With MANCOVA analysis, segment was added to the model as an independent factor. Bonferroni correction was used to compare the main effects that were found to be significant in the model. The SPSS program automatically calculates the $95 \%$ confidence interval by making Bonferroni correction, and for this, Type 1 error is guaranteed.

\section{Results}

The demographic characteristics of the patients according to groups are shown in Table 1. No significant difference was determined between the groups in respect of age, gender, BMI, and duration of $\operatorname{LBP}(p=0.631, p=0.808, p=0.815, p=0.737$, respectively). 
Table 1

Comparisons of the age, gender, BMI, duration of pain and pain severity (VAS score) of the patients according to the groups

\begin{tabular}{|c|c|c|c|c|c|c|c|c|c|}
\hline & \multicolumn{2}{|c|}{ Healthy $(n=36)$} & \multicolumn{2}{|c|}{ Mechanical $(n=35)$} & \multicolumn{2}{|c|}{$\begin{array}{l}\text { Herniated Disc } \\
(n=38)\end{array}$} & \multicolumn{2}{|c|}{ Total(n=109) } & \multirow[t]{2}{*}{$\begin{array}{l}\mathrm{P} \\
\text { değeri }\end{array}$} \\
\hline & $\bar{x} \pm \sigma$ & $\begin{array}{l}\text { Median } \\
\text { (min-max) }\end{array}$ & $\bar{x} \pm \sigma$ & $\begin{array}{l}\text { Median } \\
\text { (min-max) }\end{array}$ & $\bar{x} \pm \sigma$ & $\begin{array}{l}\text { Median } \\
\text { (min- } \\
\text { max) }\end{array}$ & $\bar{x} \pm \sigma$ & $\begin{array}{l}\text { Median } \\
\text { (min-max) }\end{array}$ & \\
\hline Age(year) & $\begin{array}{l}36.36 \\
\pm \\
12.12\end{array}$ & $34(21-64)$ & $\begin{array}{l}36.97 \\
\pm 13.6\end{array}$ & $32(23-64)$ & $\begin{array}{l}37.92 \\
\pm \\
10.57\end{array}$ & $\begin{array}{l}43.5(20- \\
51)\end{array}$ & $\begin{array}{l}37.1 \\
\pm \\
12.02\end{array}$ & $38(20-64)$ & $0.631^{1}$ \\
\hline $\mathrm{BMI}\left(\mathrm{kg} / \mathrm{m}^{2}\right)$ & $\begin{array}{l}25.71 \\
\pm \\
3.63\end{array}$ & $\begin{array}{l}25.93(19.25- \\
32.79)\end{array}$ & $\begin{array}{l}25.84 \\
\pm 5.61\end{array}$ & $\begin{array}{l}24.69(18.08- \\
36.63)\end{array}$ & $\begin{array}{l}26.49 \\
\pm \\
5.14\end{array}$ & $\begin{array}{l}26.4 \\
(19.81- \\
36.2)\end{array}$ & $\begin{array}{l}26.03 \\
\pm \\
4.83\end{array}$ & $\begin{array}{l}25.71(18.08- \\
36.63)\end{array}$ & $0.815^{1}$ \\
\hline $\begin{array}{l}\text { LBP } \\
\text { duration } \\
\text { (months) }\end{array}$ & & & $\begin{array}{l}40.97 \\
\pm 59.74\end{array}$ & $8(3-192)$ & $\begin{array}{l}38.95 \\
\pm \\
51.92\end{array}$ & $\begin{array}{l}7(3- \\
240)\end{array}$ & $\begin{array}{l}39.92 \\
\pm \\
55.42\end{array}$ & $7(3-240)$ & $0.737^{2}$ \\
\hline VAS rest & & & $\begin{array}{l}1.66 \pm \\
0.8\end{array}$ & $1(1-4)$ & $\begin{array}{l}2.39 \\
\pm \\
1.37\end{array}$ & $2(1-6)$ & $\begin{array}{l}2.04 \\
\pm \\
1.18\end{array}$ & $2(1-6)$ & $0.022^{2}$ \\
\hline VAS activity & & & $\begin{array}{l}3.14 \pm \\
0.94\end{array}$ & $3(2-6)$ & $\begin{array}{l}4.37 \\
\pm \\
1.87\end{array}$ & $4(2-8)$ & $\begin{array}{l}3.78 \\
\pm \\
1.61\end{array}$ & $3(2-8)$ & $0.006^{2}$ \\
\hline Gender & \multicolumn{2}{|l|}{ n (\%) } & \multicolumn{2}{|l|}{$\mathrm{n}(\%)$} & \multicolumn{4}{|l|}{$\mathrm{n}(\%)$} & \\
\hline Male & \multicolumn{2}{|c|}{$15(41.7)$} & \multicolumn{2}{|l|}{$12(34.3)$} & \multicolumn{2}{|c|}{$14(36.8)$} & \multicolumn{2}{|c|}{$41(37.6)$} & $0.808^{3}$ \\
\hline Female & \multicolumn{2}{|c|}{$21(58.3)$} & \multicolumn{2}{|l|}{$23(65.7)$} & \multicolumn{2}{|c|}{$24(63.2)$} & \multicolumn{2}{|c|}{$68(62.4)$} & \\
\hline
\end{tabular}

\section{Examinations Of The Csa And Tcsa Of The Groups}

The mean CSA values (Table 2, Table 3) in the right-left LMF and LES showed a difference between the groups ( $p<0.001$, $p=0.002, p=0.002, p=0.010$, respectively). The mean CSA value of the right LMF was determined to be lower in the healthy control group than in the mechanical LBP group and the herniated disc group, and there was no difference between the mechanical LBP group and the herniated disc group. The mean CSA values of the left LMF and right LES was determined to be lower in the healthy control group than in the herniated disc group, and the value in the mechanical LBP group was not found to be different from the others. The mean value in the left LES was determined to be similar in the healthy control group and the mechanical LBP group, and this was lower than in the herniated disc group. The mean right-left TCSA values were determined to be significantly different between the groups. This difference was due to the mean value of the healthy control group being lower than that of the herniated disc group $(p<0.001)$. 
Table 2

Comparison of the groups according to CSA and TCSA, gender, segment, age, and BMI

\begin{tabular}{|c|c|c|c|c|c|c|c|c|c|c|c|}
\hline & & \multicolumn{2}{|l|}{ Group } & \multicolumn{2}{|l|}{ Gender } & \multicolumn{2}{|c|}{ Segment } & \multicolumn{2}{|l|}{ Age } & \multicolumn{2}{|l|}{ BMI } \\
\hline & & $p$ & $\eta^{2}$ & $\mathrm{p}$ & $\eta^{2}$ & $p$ & $\eta^{2}$ & $\mathrm{p}$ & $\eta^{2}$ & $\mathrm{p}$ & $\eta^{2}$ \\
\hline \multirow[t]{4}{*}{ CSA } & Right LMF & $<0.001$ & 0.062 & $<0.001$ & 0.148 & $<0.001$ & 0.536 & 0.291 & 0.003 & 0.021 & 0.017 \\
\hline & Left LMF & 0.002 & 0.039 & $<0.001$ & 0.190 & $<0.001$ & 0.554 & 0.972 & $<0.001$ & 0.001 & 0.037 \\
\hline & Right LES & 0.002 & 0.039 & $<0.001$ & 0.174 & $<0.001$ & 0.163 & 0.028 & 0.015 & $<0.001$ & 0.126 \\
\hline & Left LES & 0.010 & 0.029 & $<0.001$ & 0.124 & $<0.001$ & 0.145 & 0.001 & 0.037 & $<0.001$ & 0.139 \\
\hline \multirow[t]{2}{*}{ TCSA } & $\begin{array}{l}\text { Right LMF + } \\
\text { LES }\end{array}$ & $<0.001$ & 0.067 & $<0.001$ & 0.236 & 0.085 & 0.015 & 0.145 & 0.007 & $<0.001$ & 0.123 \\
\hline & $\begin{array}{l}\text { Left LMF + } \\
\text { LES }\end{array}$ & $<0.001$ & 0.048 & $<0.001$ & 0.219 & 0.057 & 0.018 & 0.002 & 0.031 & $<0.001$ & 0.164 \\
\hline
\end{tabular}

The mean CSA and TCSA values in all the muscle groups were significantly different in the groups according to gender $(p<0.001)$ (Table 2, Table 3). The CSA and TCSA values of males were found to be higher than those of females in all 3 groups.

The CSA values were statistically significantly different in all the groups according to the segments (L3-L4,L4-L5,L5-S1) $(p<0.001)$ (Table 2, Table 3). In all the groups, the largest LMF CSA was determined at L5-S1 and the smallest at L3-L4, and the largest LES CSA was in the L3-L4 segment and the smallest in the L5-S1.

In the comparisons of asymmetry the CSA and TCSA showed no difference between all the groups ( $p>0.05)$. No significant difference was determined in the mean right and left mean TCSA values according to segments $(p>0.05)($ Table 2$)$. 
Table 3

The relationship between the segments, gender and CSA and TCSA measurements of the groups

\begin{tabular}{|c|c|c|c|c|c|c|}
\hline & $\begin{array}{l}\text { Rigth LMF } \\
\text { (CSA) }\end{array}$ & $\begin{array}{l}\text { Left LMF } \\
\text { (CSA) }\end{array}$ & $\begin{array}{l}\text { Rigth LES } \\
\text { (CSA) }\end{array}$ & $\begin{array}{l}\text { Left LES } \\
\text { (CSA) }\end{array}$ & Rigth TCSA & Left TCSA \\
\hline \multicolumn{7}{|l|}{ Groups } \\
\hline Healthy & $\begin{array}{l}936.92 \pm \\
262.59^{a}\end{array}$ & $\begin{array}{l}945.09 \pm \\
261.6^{\mathrm{a}}\end{array}$ & $\begin{array}{l}1640.85 \pm \\
450.58^{\mathrm{a}}\end{array}$ & $\begin{array}{l}1679.92 \pm \\
469.33^{\mathrm{a}}\end{array}$ & $\begin{array}{l}2577.77 \pm \\
455.4^{\mathrm{a}}\end{array}$ & $\begin{array}{l}2625.01 \pm \\
493.37^{a}\end{array}$ \\
\hline Mechanical & $\begin{array}{l}1014.42 \pm \\
352.06^{\mathrm{b}}\end{array}$ & $\begin{array}{l}989.63 \pm \\
331.65^{a b}\end{array}$ & $\begin{array}{l}1686.01 \pm \\
651.16^{a b}\end{array}$ & $\begin{array}{l}1668.63 \pm \\
615.93^{a}\end{array}$ & $\begin{array}{l}2700.43 \pm \\
799.12^{\mathrm{ab}}\end{array}$ & $\begin{array}{l}2658.26 \pm \\
716.84^{a}\end{array}$ \\
\hline $\begin{array}{l}\text { Herniated } \\
\text { Disc }\end{array}$ & $\begin{array}{l}1054.67 \pm \\
295.52^{b}\end{array}$ & $\begin{array}{l}1032.46 \pm \\
282.93^{\mathrm{b}}\end{array}$ & $\begin{array}{l}1849.68 \pm \\
489.49^{\mathrm{b}}\end{array}$ & $\begin{array}{l}1849.46 \pm \\
525.05^{\mathrm{b}}\end{array}$ & $\begin{array}{l}2904.34 \pm \\
563.32^{\mathrm{b}}\end{array}$ & $\begin{array}{l}2881.92 \pm \\
574.16^{b}\end{array}$ \\
\hline \multicolumn{7}{|l|}{ Gender } \\
\hline Male & $\begin{array}{l}831.78 \pm \\
214.83\end{array}$ & $\begin{array}{l}839.29 \pm \\
197.61\end{array}$ & $\begin{array}{l}2335.76 \pm \\
533.98\end{array}$ & $\begin{array}{l}2281.17 \pm \\
522.29\end{array}$ & $\begin{array}{l}3167.54 \pm \\
666.39\end{array}$ & $\begin{array}{l}3120.46 \pm \\
617.87\end{array}$ \\
\hline Female & $\begin{array}{l}665.76 \pm \\
135.36\end{array}$ & $\begin{array}{l}663.62 \pm \\
140.56\end{array}$ & $\begin{array}{l}1688.35 \pm \\
319.48\end{array}$ & $\begin{array}{l}1705.65 \pm \\
369\end{array}$ & $\begin{array}{l}2354.12 \pm \\
379.55\end{array}$ & $\begin{array}{l}2369.26 \pm \\
410.97\end{array}$ \\
\hline \multicolumn{7}{|l|}{ Segment } \\
\hline$L 3-L 4$ & $\begin{array}{l}728.21 \pm \\
187.05^{a}\end{array}$ & $\begin{array}{l}1041.7 \pm \\
225.95^{a}\end{array}$ & $\begin{array}{l}1238.65 \pm \\
257.98^{a}\end{array}$ & $\begin{array}{l}728.21 \pm \\
187.05^{a}\end{array}$ & $\begin{array}{l}1041.7 \pm \\
225.95\end{array}$ & $\begin{array}{l}1238.65 \pm \\
257.98\end{array}$ \\
\hline$\angle 4-\angle 5$ & $\begin{array}{l}729.7 \pm \\
184.47^{b}\end{array}$ & $\begin{array}{l}1016.83 \pm \\
206.3^{b}\end{array}$ & $\begin{array}{l}1223.02 \pm \\
246.76^{b}\end{array}$ & $\begin{array}{l}729.7 \pm \\
184.47^{a}\end{array}$ & $\begin{array}{l}1016.83 \pm \\
206.3\end{array}$ & $\begin{array}{l}1223.02 \pm \\
246.76\end{array}$ \\
\hline L5-S1 & $\begin{array}{l}1931.87 \pm \\
517.87^{c}\end{array}$ & $\begin{array}{l}1768.09 \pm \\
386.43^{\mathrm{c}}\end{array}$ & $\begin{array}{l}1484.5 \pm \\
603.45^{c}\end{array}$ & $\begin{array}{l}1931.87 \pm \\
517.87^{\mathrm{b}}\end{array}$ & $\begin{array}{l}1768.09 \pm \\
386.43\end{array}$ & $\begin{array}{l}1484.5 \pm \\
603.45\end{array}$ \\
\hline
\end{tabular}

In the comparison of the CSA and TCSA values according to age groups, the right and left LES CSA and left TCSA values were found to be related to age $(p=0.028, p=0.001, p=0.002$, respectively) (Table 2$)$. In the evaluations of the correlations with age within each group, a weak negative correlation was determined in the healthy control group between age and the left LES CSA and the left LMF+LES TCSA (Table 4). In the mechanical LBP group, there was found to be a weak-moderate correlation between age and the right-left LES CSA and the right-left LMF+LES TCSA values (Table 4). No significant correlation was determined with age in the herniated disc group (Table 4).

In the comparisons of the CSA and TCSA values of the groups according to BMI, a positive correlation was determined between BMI and the CSA and TCSA values of all the muscles ( $p=0.021, p=0.001, p<0.001$, respectively) (Table 2). In the healthy control group, a weak positive correlation was detrermined between BMI and the left LMF CSA and the left LMF+LES TCSA. In the mechanical LBP group, a significant positive correlation was found with all the measurements. In the herniated disc group, a weak positive correlation was determined between BMI and the right LES CSA (Table 4).

No significant correlations were determined between the duration of LBP and the CSA and TCSA values (Table 4). In the mechanical LBP group, there was determined to be a significant negative weak-moderate correlation between the VAS resting score and right-left LMF and left LES CSA, and the right-left LMF+LES TCSA values. A significant negative weakmoderate correlation was determined between the VAS activity score and right-left LMF CSA, and the right-left LMF+LES TCSA values. No significant correlation with VAS scores was determined in the herniated disc group. 
Table 4

Correlations between the groups of age, BMI, low back pain duration, and VAS scores

\begin{tabular}{|c|c|c|c|c|c|c|c|}
\hline Group & & Parameters & Age & BMI & $\begin{array}{l}\text { LBP } \\
\text { duration }\end{array}$ & $\begin{array}{l}\text { VAS } \\
\text { rest }\end{array}$ & $\begin{array}{l}\text { VAS } \\
\text { activity }\end{array}$ \\
\hline \multirow{6}{*}{$\begin{array}{l}\text { Mechanical } \\
\text { Group }\end{array}$} & \multirow[t]{4}{*}{ CSA } & Right LMF (mm²) & 0.178 & $0.209 *$ & 0.068 & $-0.570 \star \star$ & $-0.485^{\star \star}$ \\
\hline & & Left LMF $\left(\mathrm{mm}^{2}\right)$ & 0.170 & $0.243^{\star}$ & 0.101 & $-0.413^{*}$ & $-0.346^{\star}$ \\
\hline & & Right LES (mm² ) & $0.423^{\star *}$ & $0.506^{* *}$ & 0.204 & -0.294 & -0.275 \\
\hline & & Left LES $\left(\mathrm{mm}^{2}\right)$ & $0.359 * *$ & $0.549 * *$ & 0.216 & $-0.380 *$ & -0.323 \\
\hline & \multirow[t]{2}{*}{ TCSA } & )$^{\text {Right LMF + LES }\left(\mathrm{mm}^{2}\right.}$ & $0.403^{\star *}$ & $0.537 * \star$ & 0.153 & $-0.431 \star \star$ & $-0.368^{*}$ \\
\hline & & Left LMF + LES $\left(\mathrm{mm}^{2}\right)$ & $0.394 * \star$ & $0.570 * \star$ & 0.207 & $-0.448 * \star$ & $-0.365^{\star}$ \\
\hline \multirow{6}{*}{$\begin{array}{l}\text { Herniated Disc } \\
\text { group }\end{array}$} & \multirow[t]{4}{*}{ CSA } & Right LMF (mm²) & -0.064 & 0.031 & -0.012 & -0.142 & -0.002 \\
\hline & & Left LMF (mm²) & -0.057 & 0.042 & -0.083 & -0.252 & -0.038 \\
\hline & & Right LES (mm² $)$ & -0.037 & $0.249 * \star$ & -0.098 & -0.210 & -0.071 \\
\hline & & Left LES $\left(\mathrm{mm}^{2}\right)$ & -0.031 & 0.175 & -0.193 & -0.112 & 0.063 \\
\hline & \multirow[t]{2}{*}{ TCSA } & )$^{\text {Right LMF + LES }\left(\mathrm{mm}^{2}\right.}$ & -0.110 & 0.176 & -0.118 & -0.236 & -0.086 \\
\hline & & Left LMF + LES $\left(\mathrm{mm}^{2}\right)$ & -0.071 & $0.185^{\star}$ & -0.198 & -0.128 & 0.091 \\
\hline \multirow[t]{6}{*}{ Healthy group } & \multirow[t]{4}{*}{ CSA } & Right LMF (mm²) & 0.086 & 0.166 & - & - & - \\
\hline & & Left LMF $\left(\mathrm{mm}^{2}\right)$ & 0.040 & $0.206^{*}$ & - & - & - \\
\hline & & Right LES $\left(\mathrm{mm}^{2}\right)$ & -0.172 & 0.068 & - & - & - \\
\hline & & Left LES $\left(\mathrm{mm}^{2}\right)$ & $-0.228^{\star}$ & 0.154 & - & - & - \\
\hline & \multirow[t]{2}{*}{ TCSA } & )$^{\text {Right LMF + LES }\left(\mathrm{mm}^{2}\right.}$ & -0.121 & 0.63 & - & - & - \\
\hline & & Left LMF + LES $\left(\mathrm{mm}^{2}\right)$ & $-0.196^{*}$ & $0.255^{\star \star}$ & - & - & - \\
\hline
\end{tabular}

\section{Examination Of Fat Infiltration Of The Groups}

In the examinations of fat infiltration according to the groups, significant differences were determined between the right-left LMF and left LES groups ( $p=0.007, p<0.001, p=0.026$, respectively) (Table 5). The rate of fat infiltration $<10 \%$ was determined to be higher in the healthy control group than in the mechanical LBP group and in the herniated disc group, and the rates of $10-50 \%$ and $>50 \%$ fat infiltration were higher in the mechanical LBP group and the herniated disc group than in the healthy control group. 
Table 5

Comparison of fat infiltrations between groups (Simplified 3-degree system)

\begin{tabular}{|c|c|c|c|c|c|}
\hline $\mathbf{N}(\%)$ & Healthy group & Mechanical group & Herniated Disc group & Total & $P *$ \\
\hline \multicolumn{6}{|c|}{ Fat infiltration Right LMF } \\
\hline$<10 \%$ & $46(42.6)^{a}$ & $21(20)^{b}$ & $38(33.3)^{\mathrm{ab}}$ & $105(32.1)$ & \multirow[t]{3}{*}{0.007} \\
\hline $10 \%-50 \%$ & $62(57.4)^{a}$ & $82(78.1)^{b}$ & $75(65.8)^{\mathrm{ab}}$ & $219(67)$ & \\
\hline$>50 \%$ & $0(0)^{a}$ & $2(1.9)^{a}$ & $1(0.9)^{a}$ & $3(0.9)$ & \\
\hline \multicolumn{6}{|c|}{ Fat infiltration Left LMF } \\
\hline$<10 \%$ & $49(45.4)^{a}$ & $19(18.1)^{b}$ & $42(36.8)^{a}$ & 110 (33.6) & \multirow[t]{3}{*}{$<0.001$} \\
\hline $10 \%-50 \%$ & $59(54.6)^{a}$ & $83(79)^{b}$ & $71(62.3)^{a}$ & $213(65.1)$ & \\
\hline$>50 \%$ & $0(0)^{a}$ & $3(2.9)^{a}$ & $1(0.9)^{a}$ & $4(1.2)$ & \\
\hline \multicolumn{6}{|c|}{ Fat infiltration Right LES } \\
\hline$<10 \%$ & $38(35.2)$ & $24(22.9)$ & $38(33.3)$ & $100(30.6)$ & \multirow[t]{3}{*}{0.239} \\
\hline $10 \%-50 \%$ & $68(63)$ & $76(72.4)$ & $73(64)$ & $217(66.4)$ & \\
\hline$>50 \%$ & $2(1.9)$ & $5(4.8)$ & $3(2.6)$ & $10(3.1)$ & \\
\hline \multicolumn{6}{|c|}{ Fat infiltration Left LES } \\
\hline$<10 \%$ & $41(38)^{a}$ & $25(23.8)^{b}$ & $39(34.2)^{\mathrm{a}}$ & $105(32.1)$ & \multirow[t]{3}{*}{0.026} \\
\hline $10 \%-50 \%$ & $65(60.2)^{a}$ & $73(69.5)^{a}$ & $74(64.9)^{\mathrm{a}}$ & $212(64.8)$ & \\
\hline$>50 \%$ & $2(1.9)^{a}$ & $7(6.7)^{a}$ & $1(0.9)^{a}$ & $10(3.1)$ & \\
\hline
\end{tabular}

Fat infiltration in the lumbar paraspinal muscles was observed at a higher rate in females than in males (Table 6). The distributions of right-left LMF $(p=0.001)$ and right-left LES fat infiltration showed a significant difference according to gender $(p=0.009, p=0.002)$.

Fat infiltration according to segments (L3-L4,L4-L5,L5-S1) showed a significant difference $(p<0.001)($ Table 6). Fat infiltration in the right-left LMF and LES was seen at the lowest level in L3-L4, and at the highest level in L5-S1. No statistically significant correlation was determined between BMI and fat infiltration ( $p>0.05$ ) (Table 6). 
Table 6

Evaluation of fat infiltration by gender, segments and BMI values

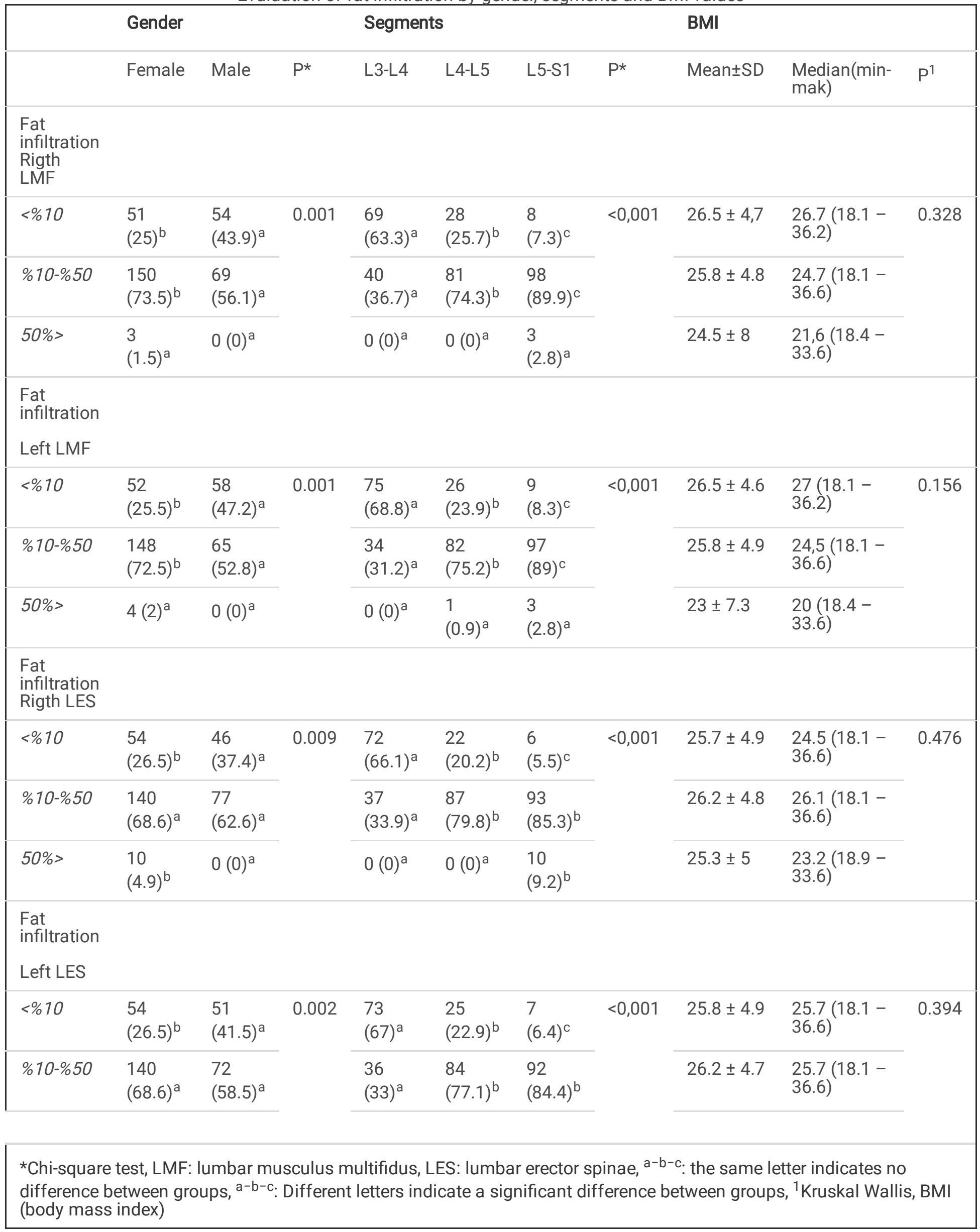




\begin{tabular}{|c|c|c|c|c|c|c|c|}
\hline \multicolumn{3}{|c|}{ Gender } & \multicolumn{3}{|c|}{ Segments } & \multicolumn{2}{|l|}{ BMI } \\
\hline $50 \%>$ & $\begin{array}{l}10 \\
(4.9)^{b}\end{array}$ & $0(0)^{a}$ & $0(0)^{a}$ & $0(0)^{a}$ & $\begin{array}{l}10 \\
(9.2)^{b}\end{array}$ & $24.6 \pm 5.6$ & $\begin{array}{l}22.1(18.1- \\
33.6)\end{array}$ \\
\hline \multicolumn{8}{|c|}{$\begin{array}{l}{ }^{*} \text { Chi-square test, LMF: lumbar musculus multifidus, LES: lumbar erector spinae, }{ }^{a-b-c} \text { : the same letter indicates no } \\
\text { difference between groups, }{ }^{a-b-c} \text { : Different letters indicate a significant difference between groups, }{ }^{1} \text { Kruskal Wallis, BM } \\
\text { (body mass index) }\end{array}$} \\
\hline
\end{tabular}

No significant correlation was determined between the duration of LBP, VAS resting and activity scores, and the LMF and LES fat infilitration (Table 7). In the mechanical LBP group, a positive weak correlation was determined between the VAS resting score and left LMF fat infiltration, but not to a statistically significant level $(p=0.290)$. In the herniated disc group, a positive weak correlation was determined between the duration of LBP, and right-left LMF and right-left LES fat infiltration, but not to a statistically significant level, $(p=0.251, p=0.263, p=0.238, p=0.253$, respectively). No statistically significant correlation was determined between age and fat infiltration $(p>0.05)$.

Table 7

Evaluation of the relationship between pain duration and severity of pain and fat infiltration

\begin{tabular}{|lllll|}
\hline \multirow{2}{*}{ Mechanical group } & LBP duration & VAS rest & VAS activity \\
& Right LMF & -0.012 & 0.197 & 0.126 \\
\hline Left LMF & -0.231 & 0.290 & 0.126 \\
\hline Right LES & 0.107 & 0.144 & 0.130 \\
\hline Herniated Disc group & Left LES & 0.040 & 0.184 & 0.126 \\
\cline { 2 - 4 } & Right LMF & 0.251 & 0.112 & 0.026 \\
\cline { 2 - 4 } & Left LMF & 0.263 & -0.026 & -0.100 \\
\cline { 2 - 4 } & Right LES & 0.238 & -0.058 & -0.161 \\
\cline { 2 - 4 } & Left LES & 0.253 & 0.046 & -0.048 \\
\hline LMF: lumbar musculus multifidus, LES: lumbar erector spinae, LBP: Low back pain, VAS: Visual Analog Scale \\
\hline
\end{tabular}

\section{Discussion}

The results of this study did not determine a consistent correlation between LBP and the CSA and TCSA of the LMF and LES. Measurement of the morphology of the lumbar paraspinal muscles has become a focus point of recent research related to the etiology of $\operatorname{LBP}[2,5,15,16,28,48]$. It has been suggested that dysfunction of these muscles is an important factor in the etiology of LBP and in it becoming chronic $[16,48]$. Previous studies have shown an association between paraspinal muscle atrophy and $\operatorname{LBP}[2,15,16,25,28,29,47,49]$ and fat infiltration $[16,17,48,50-53]$. Some of these studies have reported that in chronic LBP there is atrophy only in the LMF and there is no change in the LES [15, 49,54, 55], some have shown atrophy in both the LMF and LES [16], some have reported a smaller CSA of the LMF, psoas, and quadratus lumborum [47], and others have found no difference in the CSA of either the LMF and LES [22, 56-58]. Moreover, several researchers have reported that compared to healthy individuals there are no significant differences in the dimensions of paraspinal muscles $[32,52,53,59-62]$ or fat content $[15,28,48]$.

In the current study, the CSA and TCSA values of the LMF and LES obtained in the healthy control group were lower than those of the mechanical LBP and herniated disc groups. This was thought to be due to the pseudohypertrophy mechanism. The CSA basically represents the total number of muscle fibres with, to a lesser degree, the dimensions of the fibres [25] and 
fat content of the muscle [29]. Dystrophic muscles may not decrease the muscle measurement, and this phenomenon is stated as pseudohypertrophy of fat deposits localised within the musccle fibres [16]. In LBP, impaired neuromuscular function may cause histological changes in the muscle and thereby, atrophy [17]. However, the muscle CSA may decrease not because of fat infiltration formed in the muscle bundles [44]. Muscle density is a marker of muscle degeneration, and represents the number of muscle fibres, the individual muscle fibre area, and the integrity of the contraction material [63]. In the current study, the amount of muscle seen visually on the axial slices of the mechanical LBP goup and the herniated disc group was lower than in the healthy control group, and the fat infiltration was greater, both visually and statistically in the two LBP groups compared to the healthy control group. Therefore, in individuals with chronic LBP, despite the reduced functional CSA (FCSA) in muscles, the pseudohypertrophy mechanism can be assumed to be a reason for no change or an increase in CSA associated with the rate of increasing fat infiltration. Thus, to determine whether or not there is actual muscle mass loss, and thereby muscle degeneration, it can be considered important to examine FCSA, rather than CSA or TCSA, to reach accurate results.

Previous studies have shown that males have greater CSA and higher paraspinal muscle endurance than females, young individuals have greater muscle density than older individuals, and those of lower body weight have higher paraspinal muscle density than those who are overweight [59]. In the current study, the CSA and TCSA values of males in all the groups were found to be higher than those of females $[2,14,28-31,41]$.

$\mathrm{BMI}$ and bodyweight have been stated to be associated with larger muscle CSA [32]. Some authors have determined a significant correlation between BMI and the LMF and LES muscle values and an association of BMI with paraspinal muscle changes [25]. However, there are also studies with results showing no correlaation between BMI and CSA [16, 17, 46]. Kalichman et al determined a low but statistically significant negative correlation between paraspinal muscle density and $\mathrm{BMI}$, and stated that this correlation was significant in females but not in males [44]. In the current study, a weak moderate level correlation was determined between BMI and CSA and TCSA.

Consistent with the findings in literature, when compared according to segments (L3-L4,L4-L5,L5-S1) the lowest CSA and TCSA values were determined at L3-L4, and the highest at the level of L5-S1 [14, 16, 46, 61, 64-67].

When literature was examined, most studies were of comparisons of asymmetry between the symptomatic and symptomatic sides with groups of acute, chronic, and with and without root compression pain [14, 28, 66-68]. The results of previous studies of healthy individuals have shown symmetry of the LMF between sides. Hides et al examined asymptomatic subjects between 1992 and 1994 and showed a difference of $3 \pm 4 \%$ between the widest edge and the other side [65]. More recently, Stokes et al reported this rate to be $7.2 \%-9.6 \%$ at the L4-L5 level compared with the smallest edge [31]. Based on these results, it has been stated that asymmetry of $>10 \%$ could be seen as potentially abnormal [44]. In the comparisons of asymmetry in the current study, no significant difference was found between the TCSA values of all the groups. This result was thought to be related to the balanced distribution of fat infiltration in paravertebral muscles as the pain was not acute, unilateral or root compression pain in the mechanical LBP and lumbar disc herniation groups.

There is a limited number of studies showing a relationship between the duration of pain and CSA [5] and similar to the current study, the majority of studies have shown no significant relationship between the duration of pain and CSA [2, 45, 61, 69].

Although fat infiltration seems to be a late stage of muscle degeneration, LMF fat infiltration is commonly and strongly related independently of body composition [17]. In obese individuals, body fat accumulates naturally in the muscles throughout the back muscle system, but does not settle at the level of the last twwo lumbar vertebrae where spine problems are often seen. That fat infiltration is found in these two problematic areas tends to show that LBP is initiated by muscle changes [44]. There is no clarity in literature about the relationship between fat infiltration and chronic LBP [27, 28, 53]. Some studies have reported a relationship between LBP and fat infiltration only in the LMF [46, 50,51], some studies have reported a relationship with fat infiltration in both the LMF and LES $[2,17,50,52,53,59]$, and there are also studies reporting 
no relationship with fat infiltration in the LMF and/or LES [28]. In the current study, increased fat infiltration in the LMF was observed in the LBP patients compared to the healthy control group, and no significant increase was observed in the LES. The degeneration seen in the LMF muscle in chronic LBP patients is thought to be due to the anatomy, function, and innervation characteristics of the muscle.

A higher rate of fat infiltration was seen in the lumbar paraspinal muscles of females in the current study compared to males, which was consistent with the literature $[17,20,33,44]$.

The amount of intramuscular fat in the LMF and LES has been shown to be significantly increased in the lower lumbar segments compared to upper lumbar segments [44]. The greater paraspinal muscle atrophy (fat infiltration) seen at L5-S1 compared to L3-L4 may be related to a higher rate of degeneration and spinal pathology occurring at this level. The large angle between L5-S1 levels, and that this is the most mobile level of the spine carrying the greatest weight, greatly increase the stress on the vertebral unit. These factors are the probable reason for the paraspinal muscle changes observed at the related level [25]. Consistent with findings in literature, the current study results showed that the greatest fat infiltration was seen at L5-S1 and the least at L3-L4 [2, 15, 44, 68].

No significant relationship was determined in the current study between LBP duration and severity and fat infiltration of the LMF and LES. In studies of the relationship between fat infiltration and LBP, there is limited evidence that there is no significant relationship between fat infiltration and LBP ongoing for periods of less or more than one year [27]. The results of the current study were consistent with the literature.

This study had some limitations, primarily the small sample size due to the difficulties of finding the same number of participants for three separate groups. However, the number of cases was sufficient according to the power analysis. Another limitation could be said to be the absence of histological data which could be compared with the imaging findings in the measurement of muscle mass.

\section{Conclusion}

The results of this study demonstrated an association between fat infiltration in the LMF and mechanical LBP and lumbar disc herniation. It can be considered that in the evaluation of muscle mass, it would be more appropriate to measure muscle atrophy associated with fat infiltration or FCSA, rather than CSA and TCSA. This may explain our inability to find a negative relationship between chronic low back pain and CSA and TCSA. There was seen to be no relationship between paraspinal muscle asymmetry and mechanical LBP and lumbar herniated disc with no root compression ongoing for longer than 3 months. A higher rate of fat infiltration was determined in females than in males. Fat infiltration was often seen at the lower lumbar vertebral levels (L4-5, L5-S1) and usually in the muscle area adjoining the vertebral body. A correlation was determined between CSA and TCSA and BMI, but no significant correlation was seen with pain duration and severity.

\section{Abbreviations}

LMF: Lumbar Musculus Multifidus, LES: Lumbar Musculus Erector Spinae, MRI: Magnetic Resonance Imaging, CSA: Crosssectional area, TCSA: Total cross-sectional area, FCSA: Functional cross-sectional area, VAS: Visual Analog Scale, LBP: Low back pain, BMI: Body mass index, LDH: lumbar disc herniation

\section{Declarations}

\section{Ethical approval and consent}

The study was conducted in compliance with the principles of the Helsinki Declaration. Approval for the study was granted by the Ethics Committee of near East University (NEU/2020/83-1160). All the participants provided informed consent. 


\section{Permission to publish}

Not applicable.

\section{Data and materials availability}

The data obtained and analyzed in this study is not available to the public because of ethical regulations and local management procedures, but can be obtained on request from corresponding author.

\section{Competing interests}

The authors have no conflict of interests to declare.

\section{Funding}

No funding for this study was provided from any source.

\section{Author Contributions}

A.Y. and T.Y. designed the study, interpreted the data, and made major contributions to the writing of the article. A.O. managed the study. A.Y. evaluated the suitability of the patients and referred potential participants to the polyclinics. All the authors examined the final draft of the manuscript, made changes, and approved it.

\section{Acknowledgements}

The authors would like to thank Radiology Specialist, Doctor Kerim Temiz for contributing to the MRI interpretations, technician, Halil Ibrahim Efe, for performing the MRI scans and the Practice Specialist, İbrahim Yeşilyurt, for assisting with addaptation of the MRI device to the study.

\section{References}

1. Rubin DI. Epidemiology and risk factors for spine pain. Neurol Clin 2007; 25: 353-371. doi:10.1016/j.ncl.2007.01.004.

2. Kader DF, Wardlaw D, Smith FW. Correlation between the MRI changes in the lumbar multifidus muscles and leg pain. Clin Radiol 2000; 55: 145-9. doi:10.1053/crad.1999.0340.

3. Andersson GBJ. Epidemiology of low back pain. Acta Orthop Scand. 1998;69(281): 28-31. doi:10.1080/17453674.1998.11744790

4. Katz JN. Lumbar disc disorders and low-back pain: socioeconomic factors and consequences. J Bone Joint Surg Am 2006; 88(2): 21-4. doi:10.2106/JBJS.E.01273.

5. Fortin M, Gibbons LE, Videman T, Battié MC. Do variations in paraspinal muscle morphology and composition predict low back pain in men? Scand J Med Sci Sports 2015: 25: 880-887. doi:10.1111/sms.12301

6. Rosatelli AL, Ravichandiran K, Agur AM. Three-dimensional study of the musculotendinous architecture of lumbar multifidus and its functional implications. Clin Anat. 2008;21(6):539-546.

7. Bogduk N. Clinical Anatomy of the Lumbar Spine And Sacrum. Amsterdam, The Netherlands: Elsevier Health Sciences; 2005.

8. MacDonald D, Moseley GL, Hodges PW. Why do some patients keep hurting their back? Evidence of ongoing back muscle dysfunction during remission from recurrent back pain. Pain. 2009;142:183-188. doi:10.1016/j. pain.2008.12.002

9. Moseley GL, Hodges PW, Gandevia SC. Deep and superficial fibers of the lumbar multifidus muscle are differentially active during volun- tary arm movements. Spine (Phila Pa 1976). 2002;27:E29-E36. 
10. Jorgensen K, Mag C, Nicholaisen T, Kato M. Muscle Fibre Distribution, Capillary Density And Enzymatic Activities In The Lumbar Paravertebral Muscles Of Young Men. Significance For Isometric Endurance. Spine, 1993; 18:1439-1450.

11. Kaigle AM, Holm SH, Hansson TH. Experimental Instability In The Lumbar Spine. Spine, 1995; 20(4):421-430. doi:10.1097/00007632-199502001-00004

12. Hodges PW, Danneels L. Changes in Structure and Function of the Back Muscles in Low Back Pain: Different Time Points, Observations, and Mechanisms. J Orthop Sports Phys Ther. 2019;49(6):464-476.

13. Noonan AM, Brown SHM. Paraspinal muscle pathophysiology associated with low back pain and spine degenerative disorders. JOR Spine. 2021;4(3):e1171.

14. Min JH, Choi HS, Rhee WI, Lee JI. Association between radiculopathy and lumbar multifidus atrophy in magnetic resonance imaging. J Back Musculoskelet Rehabil. 2013; 26:175-181. doi:10.3233/BMR-13036

15. Danneels LA, Vanderstraeten GG, Cambier DC, Witvrouw EE, De Cuyper HJ. CT imaging of trunk muscles in chronic low back pain patients and healthy control subjects. Eur Spine J 2000: 9 (4): 266-272.

https://doi.org/10.1007/s005860000190.

16. Parkkola R, Rytokoski U, Kormano M. Magnetic resonance imaging of the discs and trunk muscles in patients with chronic low back pain and healthy control subjects. Spine. 1993;18:830-836. doi:10.1097/00007632-19930600000004.

17. Kjaer P, Bendix T, Sorensen JS, Korsholm L, Leboeuf-Yde C. Are MRI-defined fat infiltrations in the multifidus muscles associated with low back pain? BMC Med. 2007: 5: 2. doi:10.1186/1741-7015-5-2

18. Kudo D, Miyakoshi N, Hongo M, Kasukawa Y, Ishikawa Y, Fujii M, et al. mrnA expressions of peroxisome proliferatoractivated receptor gamma coactivator $1 a$, tumor necrosis factor-a, and interleukin- 6 in paraspinal muscles of patients with lumbar kyphosis: a preliminary study. Clin interv Aging. 2018;13:1633.

19. Mengiardi B, Schmid MR, Boos N, Pfirrmann CWA, Brunner F, Elfering A,et al. Fat content of lumbar paraspinal muscles in patients with chronic low back pain and in asymptomatic volunteers: quantification with MR spectroscopy. Radiology 2006: 240(3): 786-792. doi:10.1148/radiol.2403050820.

20. Mannion AF. Fibre type characteristics and function of the human paraspinal muscles: normal values and changes in association with low back pain. J Electromyogr Kinesiol. 1999;9:363-377.

21. Hori Y, Hoshino M, Inage K, Miyagi M, Takahashi S, Ohyama S, et al. Isss prize In clınıcal science 2019: clinical importance of trunk muscle mass for low back pain, spinal balance, and quality of life-a multicenter cross-sectional study. Eur Spine J. 2019;28:914-992.

22. Agten A, Stevens S, Verbrugghe J, Eijnde BO, Timmermans A, Vandenabeele F. The lumbar multifidus is characterised by larger type I muscle fibres compared to the erector spinae. Anat Cell Biol. 2020;53(2):143.

23. Gao Y, Waas AM, Faulkner JA, Kostrominova TY, Wineman AS. Micromechanical modeling of the epimysium of the skeletal muscles. J Biomech. 2008;41(1):1-10. doi: 10.1016/j.jbiomech.2007.08.008.

24. Purslow PP. The structure and role of intramuscular connective tissue in muscle function. Front Physiol. 2020;11:495.

25. Fortin M, Videman T, Gibbons LE, Battie MC. Paraspinal muscle morphology and composition: a 15-yr longitudinal magnetic resonance imaging study. Med Sci Sports Exerc 2014;46:893-901. doi:10.1249/ MSS.0000000000000179

26. Fortin M, Macedo L. Multifidus and paraspinal muscle group cross-sectional areas of patients with low back pain and control patients: a systematic review with a focus on blinding. Phys Ther. 2013: 93 (7): 873-888. doi:10.2522/ptj.20120457.

27. Ranger TA, Cicuttini FM, Jensen TS, Peiris WL, Hussain SM, Fairley J, et al. Is the size and composition of the paraspinal muscles associated with low back pain? A systematic review. Spine J 2017; 17: 1729-48. doi:10.1016/j.spinee. 2017.07.002.

28. Hides J, Gilmore C, Stanton W, Bohlscheid E. Multifidus size and symmetry among chronic LBP and healthy asymptomatic subjects. Man Ther. 2008;13(1): 43-49. doi:10.1016/j.math.2006.07.017. 
29. Kalichman L, Hodges P, Li L, Guermazi A, Hunter DJ. Changes in paraspinal muscles and their association with low back pain and spinal degeneration: CT study. European Spine Journal, 2010;19(7):1136-1144. doi:10.1007/s00586009-1257-5

30. Kalichman L, Klindukhov A, Li L, Linov L. Indices of paraspinal muscles degeneration: reliability and association with facet joint osteoarthritis: feasibility study. J Spinal Disord Tech. 2016; 29(9): 465-470. doi:10.1097/BSD. 0b013e31828be943

31. Stokes M, Rankin G, Newham DJ. Ultrasound imaging of lumbar multifidus muscle: normal reference ranges for measurements and practical guidance on the technique. Man Ther. 2005;10(2):116-126. doi:/10.1016/j.math.2004.08.013.

32. Gibbons LE, Videman T, Battie MC, Kaprio J. Determinants of paraspinal muscle cross-sectional area in male monozygotic twins. Phys Ther. 1998;78(6):602-12. doi:10.1093/ptj/78.6.602.

33. Takayama K, Kita T, Nakamura H, Kanematsu F, Yasunami T, Sakanaka H, et al. New predictive index for lumbar paraspinal muscle degeneration associated with aging. Spine. 2016;41(2): E84-E90. doi:10.1097/BRS.0000000000001154.

34. Agha O, Mueller-Immergluck A, Liu M, Zhang H, Theologis AA, Clark A, et al. Intervertebral disc herniation effects on multifidus muscle composition and resident stem cell populations. JOR Spine. 2020;3:e1091.

35. Shahidi B, Hubbard JC, Gibbons MC, Ruoss S, Zlomislic V, Allen RT, et al. Lumbar multifidus muscle degenerates in individuals with chronic degenerative lumbar spine pathology. J Orthop Res. 2017;35(12):2700-2706.

36. Mazis N, Papachristou DJ, Zouboulis P, Tyllianakis M, Scopa CD, Megas P. The effect of different physical activity levels on muscle fiber size and type distribution of lumbar multifidus. A biopsy study on low back pain patient groups and healthy control subjects. Eur J Phys Rehabil Med. 2009;45(4):459-467.

37. Zhu XZ, Parnianpour M, Nordin M, Kahanovitz N. Histochemistry and morphology of erector spinae muscle in lumbar disc herniation. Spine. 1989;14(4):391-397.

38. Mannion AF, Weber BR, Dvorak J, Grob D, Müntener M. Fibre type characteristics of the lumbar paraspinal muscles in normal healthy subjects and in patients with low back pain. J Orthop Res. 1997;15(6):881-887.

39. D'Aprile P, Tarantino A, Jinkins JR, Brindicci D. The value of fat saturation sequences and contrast medium administration in MRI of degenerative disease of the posterior/perispinal elements of the lumbosacral spine. Eur Radiol 2007;17:523-531. doi:10.1007/s00330-006-0324-0.

40. Kumar Y, Hayashi D. Role of magnetic resonance imaging in acute spinal trauma: a pictorial review. BMC Musculoskelet Disord. 2016; 17: 310. doi:10.1186/s12891-016-1169-6

41. Hu ZJ, He J, Zhao FD, Fang XQ, Zhou LN, Fan SW. An assessment of the intra - and inter - reliability of the lumbar paraspinal muscle parameters using CT scan and magnetic resonance imaging. Spine. 2011; 36(13): E868-74. doi:10.1097/BRS.0b013e3181ef6b51.

42. Mysliwiec LW, Cholewicki J, Winkelpleck MD, Eis GP. MSU classification for herniated lumbar discs on MRI: toward developing objective criteria for surgical selection. Eur Spine J. 2010;19(7):1087-93. doi: 10.1007/s00586-009-1274-4.

43. Fardon DF, Milette PC; Combined Task Forces of the North American Spine Society, American Society of Spine Radiology, and American Society of Neuroradiology. Nomenclature and classification of lumbar disc pathology. Recommendations of the Combined task Forces of the North American Spine Society, American Society of Spine Radiology, and American Society of Neuroradiology. Spine (Phila Pa 1976). 2001;26(5):E93-E113. doi: 10.1097/00007632-200103010-00006.

44. Kalichman L, Carmeli E, Been E. The Association between Imaging Parameters of the Paraspinal Muscles, Spinal Degeneration, and Low Back Pain. Exp Ther Med. 2017; 2562957: 1-14. doi:10.1155/2017/2562957

45. Upadhyay B, Toms AP. CT and MRI evaluation of paraspinal muscle degeneration. Europen Society of Radiology. 2015;C-2114. doi: 10.1594/ecr2015/C-2114 
46. Hides JA, Richardson CA, Jull GA. Multifidus muscle recovery is not automatic after resolution of acute, first-episode low back pain. Spine 1996;21(23):2763-9.

47. Kamaz M, Kiresi D, Oguz H, Emlik D, Levendoglu F. CT measurement of trunk muscle areas in patients with chronic low back pain. Diagn Interv Radiol. 2007: 13(3): 144-148.

48. Lee HJ, Lim WH, Park JW, Kwon BS, Ryu KH, Lee JH, et al. The relationship between cross sectional area and strength of back muscles in patients with chronic low back pain. Ann Rehabil Med 2012: 36(2): 173-181. doi:10.5535/arm. 2012.36.2.173

49. Beneck GJ, Kulig K. Multifidus atrophy is localized and bilateral in active persons with chronic unilateral low back pain. Arch Phys Med Rehabil 2012: 93(2): 300-306. doi:10.1016/j.apmr.2011.09.017.

50. Mengiardi B, Schmid MR, Boos N, Pfirrmann CWA, Brunner F, Elfering A,et al. Fat content of lumbar paraspinal muscles in patients with chronic low back pain and in asymptomatic volunteers: quantification with MR spectroscopy. Radiology 2006: 240(3): 786-792. doi:10.1148/radiol.2403050820.

51. Gildea JE, Hides JA, Hodges PW. Size and symmetry of trunk muscles in ballet dancers with and without low back pain. J Orthop Sports Phys Ther. 2013;43:525-33. doi:10.2519/jospt.2013.4523

52. Teichtahl AJ, Urquhart DM, Wangetal Y. Fat infiltration of paraspinal muscles is associated with low back pain, disability, and structural abnormalities in community-based adults. Spine Journal. 2015; 15(7): 1593-1601. doi:10.1016/j.spinee.2015.03.039.

53. Suri P, Fry AL, Gellhorn AC. Do muscle characteristics on lumbar spine magnetic resonance imaging or computed tomography predict future low back pain, physical function, or performance? A systematic review. PM\&R 2015;7:126981. doi: 10.1016/j.pmrj.2015.04.016.

54. Reeves NP, Cholewicki J, van Dieën JH, Kaw- chuk G, Hodges PW. Are stability and instabil- ity relevant concepts for back pain? J Orthop Sports Phys Ther. 2019;49:415-424. doi:10.2519/jospt.2019.8144

55. Schabrun SM, Elgueta-Cancino EL, Hodges PW. Smudging of the motor cortex is related to the severity of low back pain. Spine (Phila Pa 1976). 2017;42:1172-1178. doi:10.1097/ BRS.0000000000000938

56. Goubert D, De Pauw R, Meeus M, Willems T, Cagnie B, Schouppe S, et al. Lumbar muscle structure and function in chronic ver- sus recurrent low back pain: a cross-sectional study. Spine J. 2017;17:1285-1296. doi:10.1016/j.spinee.2017.04.025

57. Hultman G, Nordin M, Saraste H, Ohlsèn H. Body composition, endurance, strength, cross-section- al area, and density of MM erector spinae in men with and without low back pain. J Spinal Disord. 1993;6:114-123.

58. O'Lynnger TM, Zuckerman SL, Morone PJ, Dewan MC, Vasquez-Castellanos RA, Cheng JS. Trends for spine surgery for the elderly: implications for access to healthcare in North America. Neurosurgery. 2015;77:S136-S141.

59. McLoughlin RF, D’Arcy EM, Brittain MM, Fitzgerald O, Masterson JB. The significance of fat and muscle areas in the lumbar paraspinal space: a CT study. J Comput Assisted Tomogr. 1994: 18 (2): 275-278. doi:10.1097/00004728199403000-00021

60. Ploumis A, Michailidis N, Christodoulou P, Kalaitzoglou I, Gouvas G, Beris A. Ipsilateral atrophy of paraspinal and psoas muscle in unilateral back pain patients with monosegmental degenerative disc disease. Br J Radiol. 2011: 84(1004): 709-713. doi:10.1259/bjr/58136533

61. D'Hooge R, Cagnie B, Crombez G, Vanderstraeten G, Dolphens M, Danneels L. Increased intramuscular fatty infil- tration without differences in lumbar muscle cross-sectional area during remission of unilateral recurrent low back pain. Man Ther. 2012 17(6): 584-588. doi:10.1016/j.math.2012.06.007.

62. Cuellar WA, Wilson A, Blizzard CL, Otahal P, Callisaya ML, Jones G, et al. The assessment of abdominal and multifidus muscles and their role in physical function in older adults: a systematic review. Physiotherapy. 2017; 103(1): 21-39. doi:10.1016/j.physio. 2016.06.001. 
63. Jones DA, Rutherford OM, Parker DF. Physiological changes in skeletal muscle as a result of strength training. Q J Exp Physiol. 1989; 74: 233-256. doi: 10.1113/expphysiol.1989.sp003268

64. Mannion AF, Kaser L, Weber E, Rhyner A, Dvorak J, Muntener M. Influence of age and duration of symptoms on fibre type distribution and size of the back muscles in chronic low back pain patients. Eur Spine J. 2000; 9(4): 273-281. doi:10.1007/s005860000189

65. Hides JA, Saide M, Stokes MJ, Jull GA, Cooper DH. Evidence of lumbar multifidus muscle wasting ipsilateral to symptoms in patients with acute/subacute low back pain. Spine. 1994;19(2):165-172. doi:10.1097/00007632199401001-00009.

66. Barker KL, Shamley DR, Jackson D. Changes in the cross-sectional area of multifidus and psoas in patients with unilateral back pain: the relationship to pain and disability. Spine. 2004; 29: E515-E519. doi:10.1097/01.brs.0000144405.

67. Kim WH, Lee S, Lee DY. Changes in the cross-sectional area of multifidus and psoas in unilateral sciatica caused by lumbar disc herniation. J Korean Neurosurg Soc. 2011: 50 (3): 201-204. doi:10.3340/jkns.2011.50.3.201

68. Yoshihara K, Shirai Y, Nakayama Y, Uesaka S. Histo-chemical changes in the multifidus muscle in patients with lumbar intervertebral disc herniation. Spine. 2001; 26(6):622-626. doi:10.1097/00007632-200103150-00012.

69. Ranger TA, Cicuttini FM, Jensen TS, Heritier S, Urquhart DM. Paraspinal muscle cross-sectional area predicts low back disability but not pain intensity.Spine J. 2019;19(5):862-868. doi:10.1016/j.spinee.2018.12.004

\section{Figures}

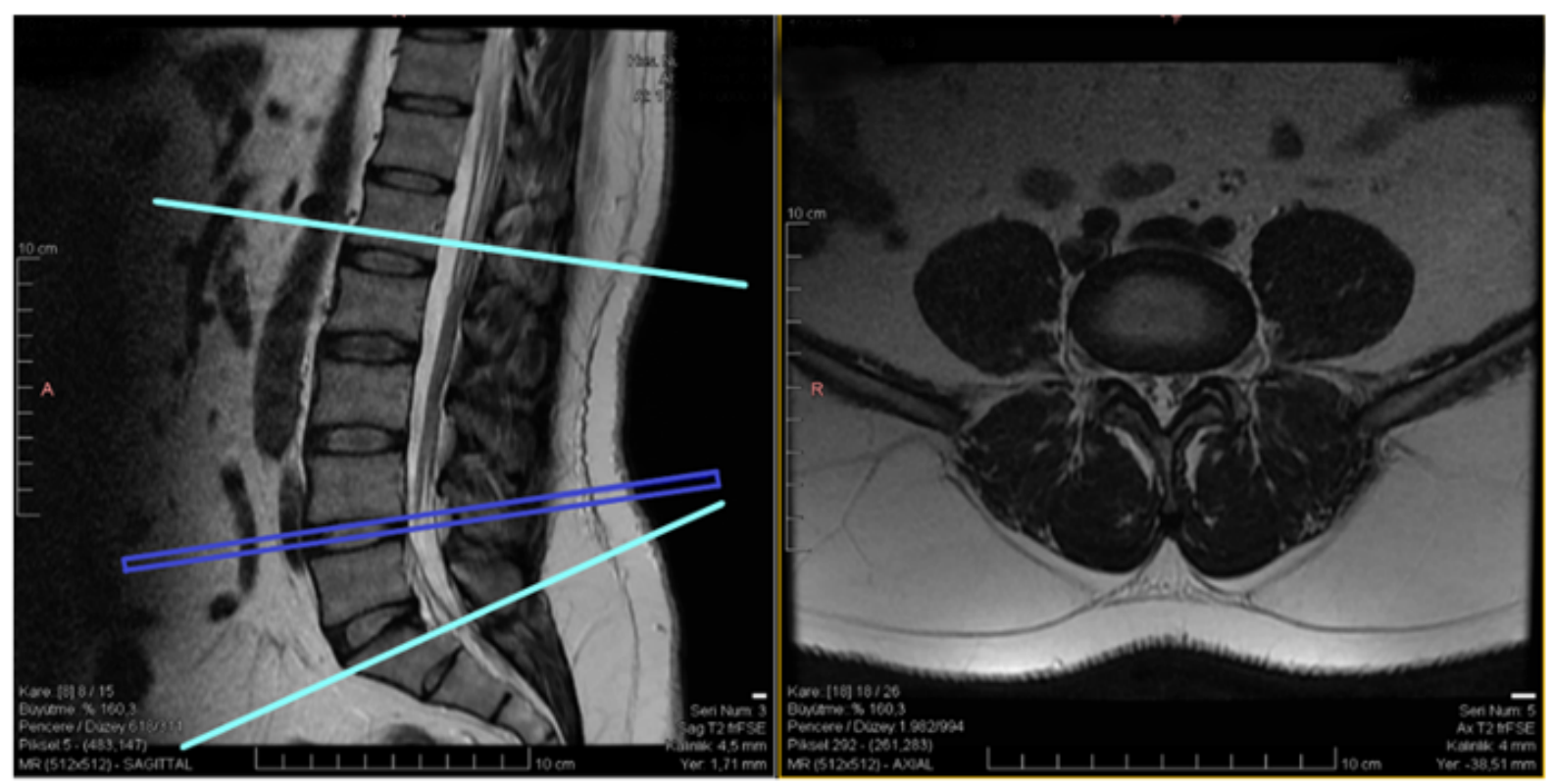

\section{Figure 1}

T2 sagittal and axial MR images of a healthy control group subject 


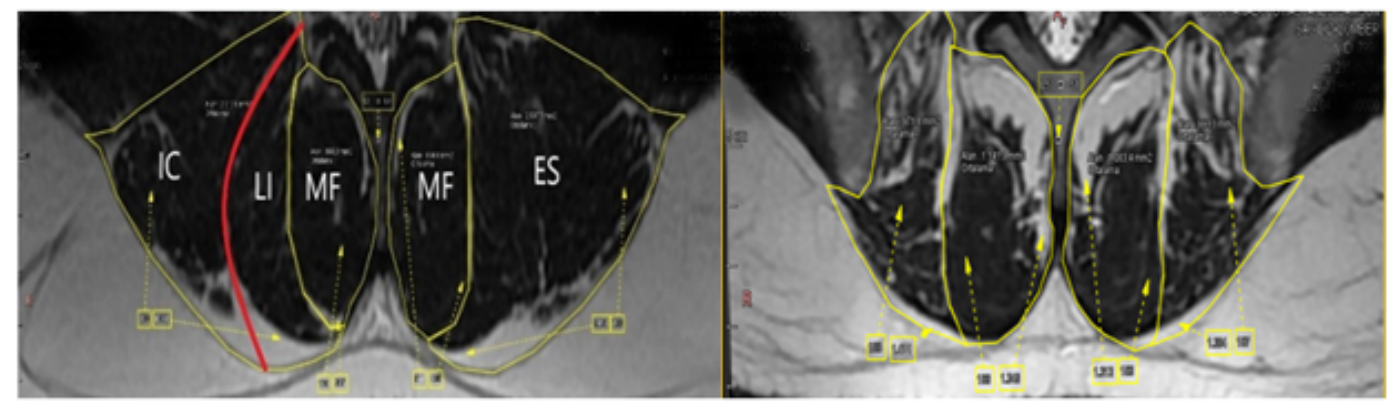

(A)

(B)

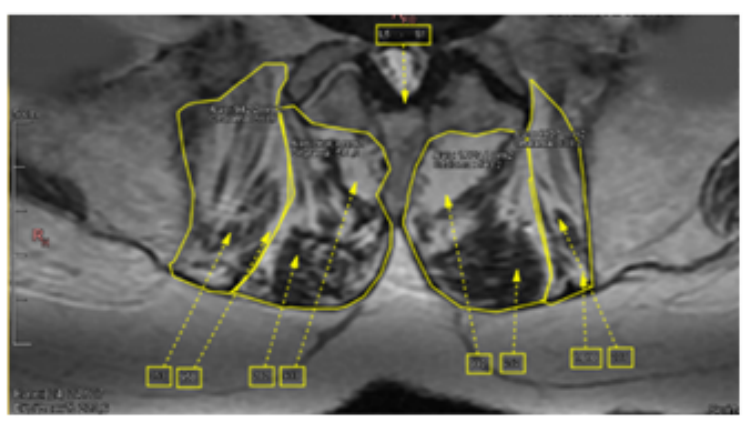

(C)

\section{Figure 2}

Fat infiltration degrees and localisation of the muscles on lumbar T2 axial MRI,

Musculus multifidus (MF), Musculus erektor spinae (ES), Musculus longissimus (LI), Musculus iliocostalis (IC) and,

(A) Grade 1: $<\% 10$ fat infiltration

(B) Grade 2: 10\%- 50\% fat infiltration

(C) Grade 3: $>50 \%$ fat infiltration 